\title{
Exoanal ultrasound of the anal sphincter: normal anatomy and sphincter defects
}

\author{
*Ursula M. Peschers Lecturer, *John O. L. DeLancey Associate Professor, \\ *Gabriel N. Schaer Lecturer, †Bernhard Schuessler Professor \\ *Department of Obstetrics and Gynecology, Division of Gynecology, The University of Michigan Medical Center, \\ Ann Arbor, Michigan, USA; †Department of Obstetrics and Gynaecology, Kantonsspital, Luzern, Switzerland
}

Objective To describe the sonographic appearance of normal anal sphincter anatomy and sphincter defects evaluated with a conventional $5 \mathrm{MHz}$ convex transducer placed on the perineum.

Design Prospective, single-blind study.

Setting Department of Obstetrics and Gynecology, University of Michigan Medical Center, USA.

Population Twenty-five women with symptoms of faecal incontinence, 11 asymptomatic nulliparous women, and 32 asymptomatic parous women.

Methods A convex scanner was placed on the perineum with the woman in lithotomy position. Images were taken at three levels of the sphincter canal. Pictures were evaluated by two examiners who were blinded to the case history of the women and to the results of each other for the presence or absence of sphincter defects.

Main outcome measures Description of anal sphincter appearance on endoanal ultrasound. Reproducibilty of the evaluation of sphincter defects.

Results The internal anal sphincter is visible as a hypoechoic circle; the external anal sphincter shows a hyperechoic pattern. Proximally the sling of the puborectalis muscle is visible. Sphincter defects were detected in 20 women. In all five women who subsequently underwent surgery, the presence and location of the defect was confirmed at the time of surgery. Examiners were in agreement $100 \%$ of the time on the presence or absence of internal defects. They disagreed in one patient on the presence of an external defect.

Conclusion Exoanal ultrasound provides information on normal anatomy and on defects of the anal sphincter.

\section{INTRODUCTION}

Ultrasound with an endoanal probe has added significantly to our ability to determine accurately the occurrence and extent of anatomical anal sphincter mechanism damage ${ }^{1,2}$. However, the specialised endoanal probes that have been used for these examinations are expensive and unavailable in many units, a fact which greatly limits acquiring these images for research and clinical management. Recent reports ${ }^{3,4}$ have documented the ability of externally applied ultrasound probes to visualise the sphincter complex but faecal incontinence symptoms were not evaluated.

This study was carried out to evaluate the ability of a conventional convex transducer placed on the perineum to visualise normal anatomy and to detect damage to the anal sphincters in patients with obstetrical injuries and/or symptoms of faecal incontinence.

Correspondence: Dr U. M. Peschers, I Frauenklinik der Universität, Maistraße 11, 80337 Munich, Germany.

\section{METHODS}

The Institutional Research Board, the Ethical Committee of the University of Michigan Medical Center, Ann Arbor, USA, gave approval for this study. Sixty-eight women were recruited from the Gynecology Clinic of the Department of Obstetrics and Gynecology, Anorectal Manometry Unit, Department of Medicine, University of Michigan Medical Center, and gave informed consent to participate in the study. Twenty-five of these women (mean age 47.3 years [SD 15.0]) had complaints of faecal incontinence and 32 parous women (mean age $50 \cdot 3$ years [SD 13.8]) and 11 nulliparous women (mean age 30.3 years [SD 8.8]) had no history of faecal incontinence. All patients and controls completed a standardised list of questions concerning symptoms of faecal urgency, discrimination between gas and stool, soiling and incontinence of gas, liquid stool and solid stool.

Exoanal ultrasound was carried out with a $5 \mathrm{MHz}$ convex scanner (Siemens SI 400, Siemens-Medical, Erlangen, Germany) with women in the lithotomy 

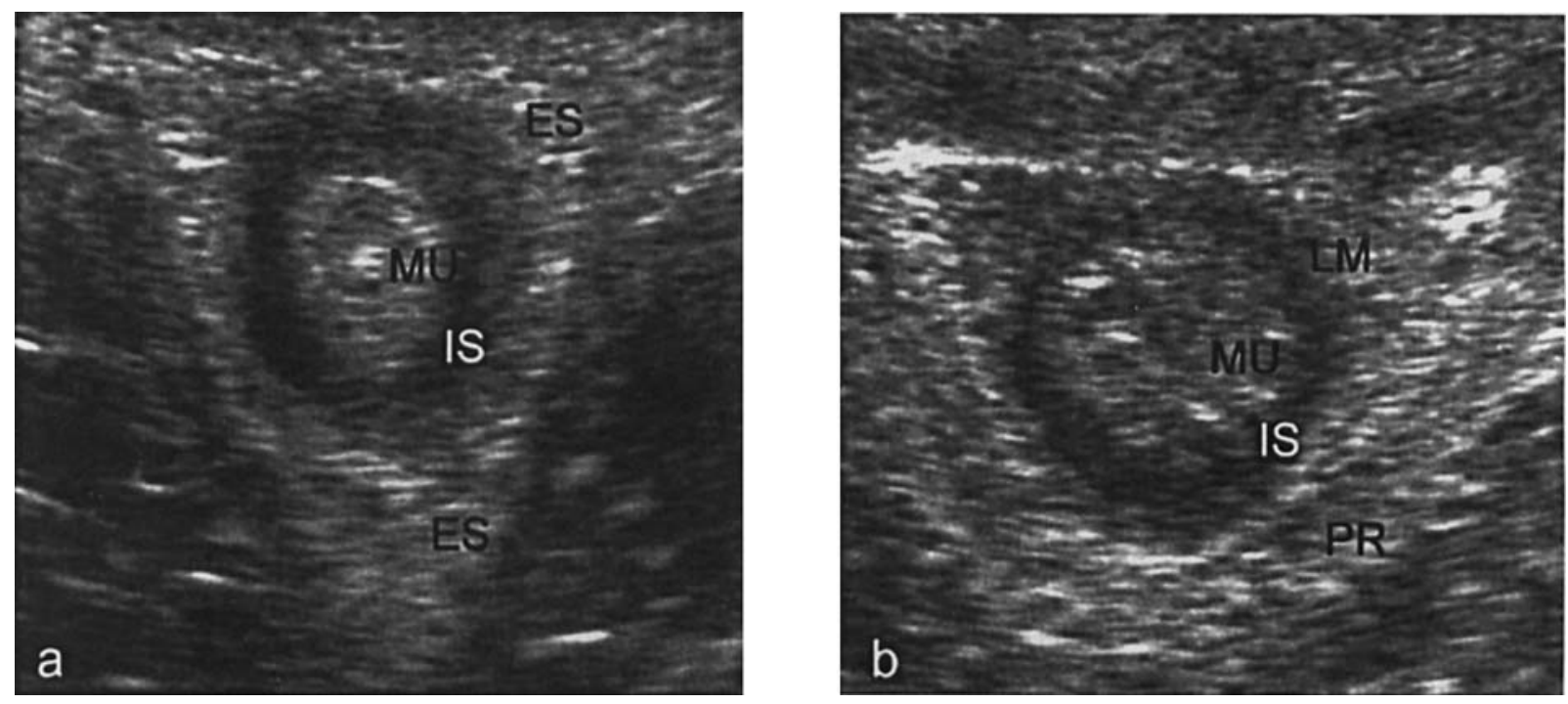

Fig. 1. Axial images of the normal anal sphincter complex: (a) mid-portion; (b) proximal part. The internal anal sphincter (IS) appears as a hypoechoic circle surrounded by the hyperechoic external anal sphincter $(E S)$. $M U=$ mucosa and submucosa, $L M=$ longitudinal muscle, $P R=$ puborectalis muscle. (The top of the image indicates the anterior part of the sphincter.)

position. The scanner was positioned on the perineal body and directed perpendicular to the longitudinal axis of the anal canal. To improve the visualisation of the anterior parts of the sphincter, a large amount of ultrasound jelly was used; the transducer was held on this 'jelly-bed' without pressure, thereby creating a greater distance between the probe and the sphincter. The angle of the transducer was adjusted until the hypoechoic ring of the internal anal sphincter had its minimum anteriorposterior diameter, indicating that the scanning plane shown was perpendicular to the longitudinal axis of the sphincter. The transducer was then moved cephalad and caudad along the anal canal maintaining the same angle until the maximum thickness of the internal sphincter was identified. The upper and lower margins of the external sphincter were studied by advancing the transducer upwards until the ' $V$ ' of the levator ani was identified and downwards till the ring of the subcutaneous external anal sphincter was visible in the area below the internal sphincter. To obtain a sagittal view of the sphincter ani muscles, the transducer was turned 90 degrees and placed over the vulva to visualise the pubic bone, the bladder and the urethra. The scanner was then rotated downward showing the vagina first and then the rectum and the anal sphincter in a sagittal plane.

A sphincter defect was defined as a persistently visible gap in the continuous structure of the internal or the external sphincter visible in multiple views. While the internal sphincter appeared hypoechoic and the external sphincter hyperechoic, defects had a middle dense echo.

The ultrasound examination was recorded on a videotape to allow subsequent detailed analysis. Two examiners, who were blinded to each other's results, determined whether anal sphincter defects were present or absent from the video records.

\section{RESULTS}

The internal anal sphincter, the external anal sphincter and the sling of the puborectalis muscle could be identified in all patients. Figure 1 shows the typical crosssectional appearance of a normal sphincter. The mucosa and submucosa are hyperechoic with a convoluted surface. Surrounding this is the circular, homogenous hypoechoic structure of the internal anal sphincter. The internal anal sphincter can be identified from the anorectal angle down to its distal end just proximal to the anal verge. The external anal sphincter is hyperechoic (Fig. 1a). The proximal part is adjacent to the sling of the puborectalis muscle (Fig. 1b), which appears hyperechoic as well. Figure 2 shows the sagittal view of the anal canal, revealing the sagittal extent of the sphincters.

Figure $3 \mathrm{a}$ shows the internal and external sphincter in a women with a chronic 4th degree perineal tear and symptoms of incontinence for gas, liquid and solid stools following spontaneous delivery of a $3800 \mathrm{~g}$ infant. The defect appears as a gap in the dark line of the internal anal sphincter and the bright band of the external anal sphincter, ranging from 10 o'clock to 20 'clock. An occult internal and external sphincter lesion is demonstrated in Fig. 3b.

The examiners were in agreement $100 \%$ of time on the presence or absence of internal sphincter defects. In one patient they disagreed on the presence of an external sphincter defect. Anal sphincter defects were detected in all women with known third or fourth 

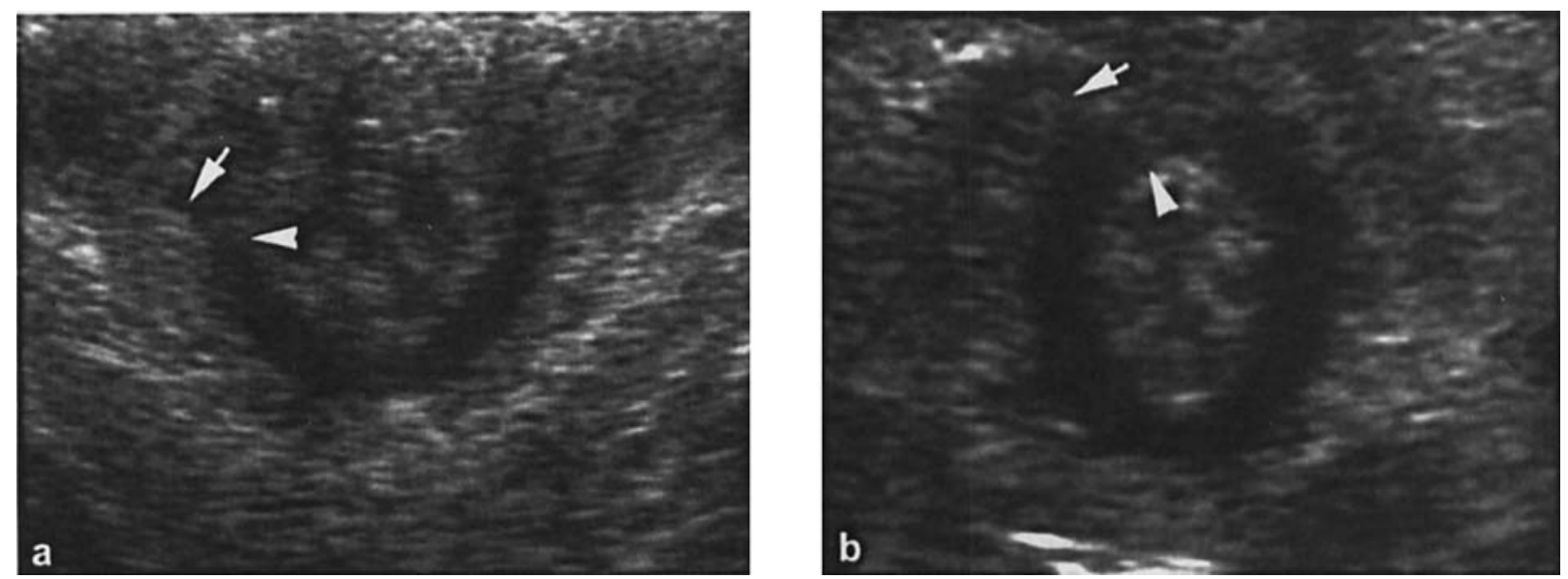

Fig. 3. Axial images of internal and external anal sphincter defects (a) in a patient with faecal incontinence after forceps delivery with a 4 th degree perineal tear; and (b) in a multiparous patient without symptoms of faecal incontinence. The defects appear as an anterior gap in the continuity of the dark circle (internal anal sphincter, arrowheads) and the hyperechoic circle (external anal sphincter, arrows). (The top of the image indicates the anterior part of the sphincter).

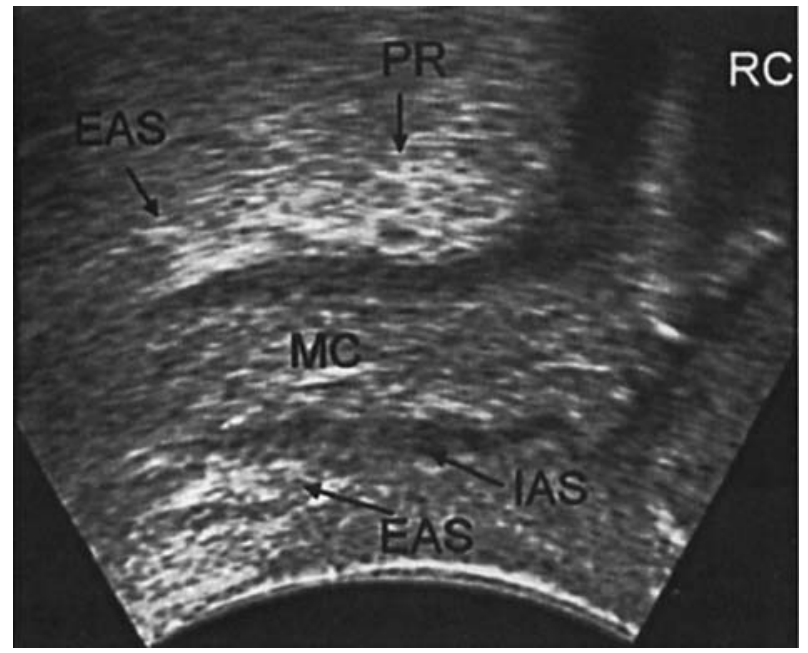

Fig. 2. Sagittal image of the normal anal sphincter complex. IS $=$ internal anal sphincter, $\mathrm{ES}=$ external anal sphincter, $\mathrm{MU}=$ mucosa, $\mathrm{PR}=$ puborectalis muscle, $\mathrm{RC}=$ rectum (top of the images: proximal, right: dorsal).

degree lacerations and in three women with symptoms of faecal incontinence without history of known sphincter damage during delivery. Symptoms reported by the patients are listed in Table 1. Eight women with sonographically demonstrable defects denied any symptoms of faecal incontinence. In 13/25 women with faecal incontinence no defect could be demonstrated. Among these women, seven were diagnosed with incontinence due to neurogenic injury, three had chronic diarrhoea, one had Crohn's disease and one colitis; another woman had developed faecal incontinence after radiation therapy for endometrial carcinoma. Sphincter reconstructive surgery was performed in five women with sonographic anal sphincter defects and faecal incontinence. The sphincter defect and its location could be confirmed in all five women.
Table 1. Symptoms of faecal incontinence in 25 patients grouped according to the presence $(n=12)$ or absence $(n=13)$ of anal sphincter defects. Values are given as $n$.

\begin{tabular}{lcc}
\hline Symptoms & Defects $(n=12)$ & No defects $(n=13)$ \\
\hline Lack of discrimination & 6 & 7 \\
Lack of awareness & 3 & 6 \\
Faecal urgency & 6 & 5 \\
Soiling of underwear/pads & 9 & 11 \\
Incontinence & & \\
$\quad$ For gas & 10 & 10 \\
$\quad$ For liquid stool & 8 & 12 \\
$\quad$ For solid stool & 4 & 6 \\
Onset of symptoms & & \\
immediately after childbirth & 7 & 3 \\
\hline
\end{tabular}

\section{DISCUSSION}

Exoanal ultrasound allows identification of anal sphincter defects. This technique is especially helpful in studying the internal anal sphincter, which is of great functional importance for maintenance of continence ${ }^{5}$. Except from ultrasound the internal anal sphincter can be assessed only indirectly by manometry, which has a low sensitivity for the detection of internal anal sphincter defects ${ }^{6}$. Exoanal ultrasound can provide an important diagnostic tool for researchers and clinicians involved in the treatment of patients with anal sphincter damage.

Problems with control of intestinal contents are multifactorial ${ }^{7}$. Hyperperistaltic conditions such as chronic diarrhoea, Crohn's disease and colitis, and neurogenic damage and sphincter disruption can lead to faecal incontinence. While gastrointestinal diseases can often be ruled out by the patient's bowel history the diagnosis of neurogenic damage involves complex, painful and invasive tests. External sphincter damage 
can be evaluated by ultrasound, EMG-mapping, manometry and palpation while the internal anal sphincter is particularly difficult to assess because, with the exception of ultrasound, it can be assessed only indirectly by manometry. Neurogenic damage to the innervation of the anal sphincter and the levator ani muscle can be caused by vaginal birth or chronic straining in constipated patients ${ }^{8-11}$. Sphincter disruption in females occurs mainly at the time of vaginal birth ${ }^{2,9}$.

An important contribution to improving the diagnosis of sphincter disruption after childbirth was made when endoanal sonography was used to study women after vaginal birth ${ }^{2,12}$. Endoanal scanning is an excellent technique to examine the anal sphincters. It has been claimed to be superior over other diagnostic tools for the evaluation of sphincter defects with a sensitivity of detecting sphincter defects of $100 \%$, compared with $89 \%$ for EMG-mapping, $67 \%$ for manometry and $56 \%$ for clinical assessment ${ }^{6}$. In studying the effect of vaginal birth on the sphincters, Sultan et al. ${ }^{2}$ documented damage of the internal anal sphincter, the external sphincter or both in $28 / 79$ primiparous women (35\%) after vaginal birth. Eight patients in this study complained of faecal urgency, one of incontinence of flatus and one of incontinence for liquid and solid stool. The importance of this study was its observation that women with obstetrical sphincter rupture had symptoms not previously suspected based on their postpartum healing and which were associated with sphincter gaps on sonographic examination. In fact, a number of women whose infant was born over an intact perineum had subcutaneous sphincter damage.

As important as these studies have been, the usefulness of endoanal sonography has been limited by the need for a specialised probe to study the sphincter mechanism. Although used in colon and rectal surgery, this probe is not generally available to obstetricians and gynaecologists who are the individuals most intimately involved in conducting the birth process and understanding birth-related pelvic floor problems. Exoanal ultrasound using a vaginal probe was firstly described by Sultan et al. ${ }^{3}$ in 1991 . Recently Sandridge and Thorp ${ }^{4}$ used vaginal ultrasound and found internal anal sphincter defects in $36 \%$ of patients and of the external anal sphincter in $29 \%$ of patients, all of whom had not spontaneously complained of symptoms of faecal incontinence. However, the authors did not confirm any of these defects surgically nor did they question their patients about symptoms of faecal incontinence and they did not provide information on the reproducibility of their measurements. The technique presented in this study was performed with a linear-curved-array scanner which is generally used in perineal ultrasound for evaluation of women presenting with urinary incontinence and vaginal prolapse $\mathrm{e}^{13,14}$. Our results show that the reproducibility for the identification of defects is high and that surgical exploration confirms defects and their location.

Faecal continence depends not only on intact sphincter muscles with functioning nerve supply but also on the puborectalis muscle and stool consistency. It is well documented that the presence of a sphincter defect is not always correlated with faecal incontinence ${ }^{2}$. In fact, only $12 / 20$ women with sphincter defects in this study actually had symptoms of faecal incontinence. On the other hand only $12 / 25$ patients with faecal incontinence had sphincter defects. The other 13 women had incontinence based on neurogenic damage or on gastrointestinal disorders with hyperparistalsis. Because faecal continence and incontinence has a multifactorial origin it must be understood that ultrasound only can be sued as one diagnostic tool among others. Its ability to distinguish between intact and damaged anal sphincters provides important information when surgical repair of the sphincters is considered.

Endoanal ultrasound has the intrinsic disadvantage of dilating the anal canal because of the size of the probe which is 17 to $22 \mathrm{~mm}$ in diameter ${ }^{15,16}$ and is incapable of sagittal scanning. On the other hand, endoanal ultrasound might provide more detailed information about anal anatomy because higher resolution and the closer contact to the examined tissue. Whether the exoanal probe provides as much information as the endoanal one remains to be seen. Exoanal ultrasound is not a method which can generally substitute endoanal ultrasound in all patients, but this method might be sufficient for the identification or exclusion of sphincter defects in women with faecal incontinence.

The sonographic identity of the visible rings in the anal sphincter have already been established ${ }^{15}$. It is generally accepted that the centrally placed mucosa and the submucosa present as hyperechoic areas surrounded by the internal anal sphincter which appears as a hypoechoic ring. The peripheral external sphincter has a mixed echogenicity with linear pattern ${ }^{15}$. The accuracy of this description was shown by Tjandra et al. ${ }^{17}$ in 1991 and by Sultan et al. ${ }^{18}$ in 1993 by comparing anal sonography and in vitro and in vivo anatomy. The correct identification of the internal anal sphincter as the hypoechoic structure has been further confirmed by scanning after iatrogenic internal sphincterotomy ${ }^{19}$. In addition, and perhaps more importantly, the description of sphincter defects by endoanal ultrasound shows a strong correlation to surgically detected defects ${ }^{6,20}$. One of the problems in diagnosing external sphincter tears with ultrasound is that the upper part of the sphincter is incomplete in females, as muscle fibers slope downwards and forwards to join together in a intact anterior ring in the mid to lower canal ${ }^{18}$. This might lead to an incorrect interpretation of defects in the upper level. 
Vaginal ultrasound of the anal sphincter corresponds to the description of the layers shown on endoanal ultrasound ${ }^{3,4}$ and so do the images obtained by a convex scanner.

\section{Acknowledgements}

Dr Peschers was supported by a grant (Pe 610/1-1) of the Deutsche Forschungsgemeinschaft (DFG). The authors acknowledge Siemens, Switzerland, who provided the ultrasound equipment for this study. We gratefully acknowledge the help of Ms M. Woods and Mr F. Hooper from the Anorectal Manometry Unit of the University of Michigan Medical Center. Reprints of this study and questionnaire used are available on request from Dr J. O. L. DeLancey, Division of Gynaecology, Department of Obstetrics and Gynaecology, $1500 \mathrm{E}$ Medical Center Drive, MPB 2202-0718, Ann Arbor, MI 48109-0718, USA.

\section{References}

1 Crawford LA, Quint EH, Pearl ML, DeLancey JOL. Incontinence following rupture of the anal sphincter during delivery. Obstet Gynecol 1993; 82: 527--531.

2 Sultan AH, Kamm MA, Hudson, CN, Thomas JN, Bartram CI. Anal sphincter disruption during vaginal delivery. N Engl J Med 1993; 329: 1905-1911.

3 Sultan AH, Loder PB, Bartram CI, Kamm MA, Hudson CN. Vaginal endosonography: new approach to image the undisturbed anal sphincter. Dis Colon Rectum 1994; 37: 1296-1299.

4 Sandridge DA, Thorp JM. Vaginal endosonography in the assessment of the anorectum. Obstet Gynecol 1995; 86: 1007-1009.

5 Bennett RC, Duthie HL. The functional importance of the internal anal sphincter. Br J Surg 1964; 51: 355-357.

6 Sultan AH, Kamm MA, Talbot IC, Nicholls RJ, Bartram CI. Anal endosonography for identifying external sphincter defects confirmed histologically. BrJ Surg 1994; 81: 463-465.
7 Madoff RD, Williams JG, Caushaj PF. Fecal Incontinence. $N$ Engl J Med 1992; 326: 1002-1007.

8 Snooks SJ, Swash M, Setchell M, Henry MM. Injury to innervation of the pelvic floor sphincter musculature in childbirth. Lancet 1984; 2: 546-550.

9 Toglia MR, DeLancey JOL. Anal incontinence and the obstetriciangynecologist. Obstet Gynecol 1994; 84: 731-740.

10 Parks AG, Swash $M$, Urich $H$. Sphincter denervation in anorectal incontinence and rectal prolapse. Gut 1977; 18: 656-665.

11 Snooks SJ Henry MM Swash M. Faecal incontinence due to external anal sphincter division in childbirth is associated with damage to the innervation of the pelvic floor musculature: a double pathology. $\mathrm{Br} J$ Obstet Gynaecol 1985; 92: 824-828.

12 Burnett SJD, Spence-Jones C, Speakman CTM, Kamm MA, Bartram CI. Unsuspected sphincter damage followed childbirth revealed by anal endosonography. Br J Radiol 1991; 64: 225-227.

13 Schaer GN, Koechli OR, Schuessler B, Haller U. Perineal ultrasound for evaluation the bladder neck in urinary stress incontinence. Obstet Gynecol 1995; 85: 220-224.

14 Creighton SM, Pearce JM, Stanton SL. Perineal video-ultrasonography in the assessment of vaginal prolapse: Early observations. $\mathrm{Br} J$ Obstet Gynaecol 1992; 99: 310-313.

15 Law PJ, Bartram CI. Anal endosonography: technique and normal anatomy. Gastrointest Radiol 1989; 14: 349-353.

16 Shaefer A, Enck P, Fuerst G, Kahn Th, Frieling T, Luebke HJ. Anatomy of the anal sphincters: comparison of anal endosonography to magnetic resonance imaging. Dis Colon Rectum 1994; 37: 777-781.

17 Tjandra JJ, Milsom JW, Stolfi VM, Lavery I, Oakley J, Fazio V. Endoluminal ultrasound defines anatomy of the anal canal and pelvic floor. Dis Colon Rectum 1992; 35: 465-470.

18 Sultan AH, Nicholls RJ, Kamm MA, Hudson CN, Beynon J, Bartram $\mathrm{Cl}$. Anal endosonography and correlation with in vitro and in vivo anatomy. Br J Surg 1993; 80: 508-511.

19 Sultan AH, Kamm MA, Nicholls RJ, Bartram CI. Prospective study of the extent of internal anal sphincter division during lateral sphincterotomy. Dis Colon Rectum 1994; 37: 1031-1033.

20 Deen KI, Kumar D, Williams JG, Olliff J, Keighley MBR. Anal sphincter defects. Correlation between endoanal ultrasound and surgery. Ann Surg 1993; 218: 20 1-205.

Received 30 January 1997

Accepted 27 May 1997 